\title{
A ÁLGEBRA PARA ENSINAR ARITMÉTICA: UM NOVO SABER NA FORMAÇÃO DE PROFESSORES PRIMÁRIOS PARA UMA SOCIEDADE MODERNA NA DÉCADA DE 1910
}

\author{
Ivone Lemos da Rocha (D)1
}

\section{Resumo}

Este texto é fruto de reflexões e considerações que vem dos resultados da dissertação da autora dessa proposta. Nesse trabalho buscou-se responder à questão: como está caracterizada a álgebra no ensino primário para resolver os problemas aritméticos nos livros didáticos de Otelo de Souza Reis e Tito Cardoso de Oliveira? Analisando esses dois livros didáticos na década de 1910, levando em consideração os saberes profissionais, descritos por Borer, em perspectiva histórica, elaborados ao longo de uma historicidade de saberes, consideramos o ambiente da docência em matemática, como um espaço em que o seu próprio exercício produz práticas e representações. Para tanto, nesse trabalho, objetiva-se ilustrar possibilidades de inserção de novos saberes na formação de professores primários, para que esta esteja dentro, naquele período, de uma sociedade dita moderna. As práticas e representações ali presentes, formuladas e apropriadas na cultura escolar, estão sendo consideradas sob os aspectos dos saberes que podem ser formalizados e sistematizados. Considera-se, assim, que no tocante aos problemas de aritmética e suas resoluções, nas duas fontes utilizadas, a álgebra é considerada um saber profissional próprio da docência. Ilustram uma álgebra para ensinar a resolver os problemas aritméticos, numa sociedade que, em seu tempo, primava por novos saberes na formação docente, para ensinar Matemática.

Palavras-chave: Saber profissional; Álgebra; Problemas aritméticos; Formação de professores; Curso primário.

\section{THE ALGEBRA TO TEACH ARITHMETIC: A NEW KNOWLEDGE IN THE TRAINING OF PRIMARY TEACHERS FOR A MODERN SOCIETY IN THE 1910 S}

\section{Abstract}

This text is the result of reflections and considerations that come from the results of the dissertation of the author of this proposal. In this work, we tried to answer the question: how is algebra characterized in primary education to solve arithmetic problems in the textbooks of Otelo de Souza Reis and Tito Cardoso de Oliveira? Analyzing these two textbooks in the 1910s, taking into account the professional knowledge, described by Borer, in historical perspective, elaborated over a historicity of knowledge, we consider the teaching environment in mathematics, as a space in which your own exercise produces practices and representations, for this purpose, in this work, the objective is to illustrate possibilities of insertion of new knowledge in the formation of primary teachers, so that it is within, in that period, a so-called

${ }^{1}$ Doutoranda no Programa de Pós-graduação em Educação, da Universidade Federal de São Paulo, UNIFESP. Membro do Grupo de Pesquisa em História da Educação Matemática - GHEMAT, Financiamento CAPES. E-mail: ivonelemos20@gmail.com

(c) (1) Pe Perspectivas em Diálogo, Naviraí, v.8, n. 16, p. 60-71, jan./abr. 2021. 
modern society. The practices and representations present there, formulated and appropriate in school culture, are being considered under aspects of knowledge that can be formalized and systematized. Thus, it is considered that with regard to arithmetic problems and their resolutions, in the two sources used, algebra is considered a professional knowledge specific to teaching. They illustrate an algebra to teach how to solve arithmetic problems, in a society that, in its time, excelled for new knowledge in teacher education, to teach Mathematics.

Keywords: Professional knowledge; Algebra; Arithmetic problems; Teacher training; Primary course.

\section{Considerações iniciais}

Este trabalho assume o objetivo de considerar resultados da dissertação ${ }^{1}$ da autora desse texto aliado ao projeto temático que está diretamente vinculado, assim como contribuir com o campo da História da Educação, da História da Educação Matemática e de estudos que estejam vinculados a pesquisar os processos que estão inseridos ideias e conceitos que visem a entender e caracterizar como esteja ilustrada uma construção de uma nova sociedade, atualizada e moderna, segundo a necessidade do período analisado.

Aliados a isso, encontra-se a inserção desses estudos aos de uma rede de pesquisadores em âmbito nacional, sob a intenção de percorrer uma historicidade presente na formação de professores e no ensino primário. Tal grupo está vinculado a um projeto maior, chamado de projeto guarda-chuva, por abarcar em si, outros subprojetos, que estejam de acordo ao tema pesquisado, ou seja, há um projeto temático em comum entre eles.

Tal projeto temático, intitulado "A matemática na formação de professores e no ensino: processos e dinâmicas de produção de um saber profissional, 1890-1990", como o próprio nome indica, busca caracterizar e ilustrar sistematizações que envolvem sua questão principal: "que matemática deverá formar o futuro professor?" (VALENTE et al., 2017, p. 9).

Tem como característica principal ser desenvolvido, em âmbito nacional, por pesquisadores e historiadores do Grupo de Pesquisa em História da Educação Matemática (GHEMAT) do Brasil e foco nos saberes passíveis de sistematização e transmissão, na formação de professores e no ensino. Esses processos ou essas dinâmicas em que ocorrem nesses ambientes, próprios do exercício da docência, em especial da docência em matemática, estamos chamando de saberes profissionais e são analisados em perspectiva histórica (LE GOFF, 1990), pois constituem uma historicidade de saberes (BURKE, 2016) a ser considerada numa determinada sociedade que a caracteriza.

Nesse sentido, podemos "sugerir que o processo histórico do professorado (passado) pode servir de base à compreensão dos problemas actuais da profissão docente (presente)" (NÓVOA, 1995, 14). Pode contribuir com aspectos contemporâneos enfrentados na formação de professores e ensino.

Estando em contato com estudos e conceitos da História Cultural, adota-se igualmente, como metodologia de análise na pesquisa, a ideia de apropriações,

${ }^{1}$ Para mais detalhes ver em: Rocha (2019). 105f. Dissertação. Mestrado em Ciências: Educação e Saúde na Infância e Adolescência - Universidade Federal de São Paulo. São Paulo.

(c) (1) (9) Perspectivas em Diálogo, Naviraí, v.8, n. 16, p. 60-71, jan./abr. 2021. 
práticas e representações (CHARTIER, 1990), que estejam presentes na cultura escolar (JULIA, 2001).

Tal perspectiva metodológica, aliada ao foco nos saberes presentes na formação de professores e no ensino, ilustra o professor que ensina matemática que produz e atua em seu ambiente, assim como contribui para a formação de uma sociedade, esperada para aquele período, faz-nos refletir sobre como os saberes estão presentes, como estão formalizados e objetivados ou sistematizados.

Assim, o GHEMAT se aproximou de outros referenciais que dissertam sobre a ótica da perspectiva histórica. Percebeu-se, nessas considerações, relações que a partir do século XIX, ainda que nos cantões suíços, estariam recebendo saberes que modificariam o panorama da formação de professores e do ensino.

Estas relações acontecem no campo das ciências da educação que intensificam tensões e trazem mudanças no campo disciplinar, no nosso caso, a matemática. Sucintamente, podemos considerar estes saberes na formação de professores como os saberes a ensinar e aqueles saberes presentes no ensino, como os saberes para ensinar (HOFSTETTER; SCHNEUWLY, 2017).

Considerando nessa perspectiva que, na docência em matemática, os saberes, apropriados, acontecem nas dinâmicas e nos processos próprios do exercício da docência, saberes objetivados e os saberes profissionais (BORER, 2017). Analisamos, como estão organizados, disponibilizados e propostos os discursos, processos e dinâmicas envolvidos.

Estes, surgem ao longo de um período numa matemática própria na formação de professores ou no ensino do curso primário, uma matemática a ensinar ou uma matemática para ensinar, respectivamente (BERTINI; MORAIS; VALENTE, 2017).

Tal perspectiva de análise proporciona ao GHEMAT aproximações com outros subprojetos como aquele intitulado, "Os problemas de aritmética no ensino primário, 1890-19401". Aliamos a este, nossa proposta de pesquisa que resultou na dissertação, base desse texto e contribuições a esses dois projetos, bem como contribuir com estudos que estejam interessados em entender aspectos de formação dessa constituição dos saberes.

\section{2. Álgebra para ensinar a resolver os problemas de aritmética: um saber profissional para o curso primário}

Ao se posicionar nas análises, sob a orientação de questões e temas de pesquisas desses dois projetos ${ }^{2}$, estabelecemos como fontes, os livros didáticos ${ }^{3}$ (CHOPPIN, 2004; 2009) de Otelo Souza Reis (1919) e o de Tito Cardoso de Oliveira (s.d $\left.\mathrm{d}^{4}.\right)$.

Com o próprio caminhar das análises 5 , ficamos, assim, delimitados na década de 1910, por serem estes os livros didáticos que apresentaram nossa caracterização a respeito dos saberes profissionais necessários para o ensino das resoluções dos problemas aritméticos, utilizando-se da álgebra.

\footnotetext{
${ }^{1}$ Financiamento da CNPq e sob coordenação de Prof. Dra Luciane de Fatima Bertini.

${ }^{2}$ Saberes profissionais do professor que ensina matemática e os problemas aritméticos no curso primário.

${ }^{3}$ Choppin $(2004$; 2009) chama-nos atenção para os diferentes sentidos léxicos para a expressão livro didático, manuais pedagógicos, entre outros. Por opção, adotamos a expressão "livros didáticos" para as fontes que utilizamos, por serem alvo de, entre outros, instruções, para alunos e professores.

${ }^{4} \mathrm{~A}$ obra analisada é da $8^{a}$ edição, sem data, porém possui indicação e prefácio de sua 4a edição, de 1919.

${ }^{5}$ Considerações parciais, foram publicadas em Rocha (2017; 2018; 2019), Bertini; Rocha (2018).
}

(c) (1) (). Perspectivas em Diálogo, Naviraí, v.8, n. 16, p. 60-71, jan./abr. 2021. 
Para esse texto procuramos responder baseado nessas fontes, na dissertação e em algumas outras análises, a questão: como está caracterizada a álgebra no ensino primário para resolver os problemas aritméticos nos livros didáticos de Reis (1919) e Tito de Oliveira (s.d.) na década de 1910?

Nesse período no Brasil, segundo Faria filho (2016, p. 139), acontece a organização dos primeiros grupos escolares, assume-se como prioridade a instrução e o aluno é visto como o centro da aprendizagem, temos o "método intuitivo", em que deveria o professor considerar os valores da "intuição, observação, enquanto momento primeiro e insubstituível da aprendizagem humana"(ibid, p. 143).

Tanuri (2000, p. 69) reforça ainda que seria importante no curso primário das "lições de coisas", a observação e a percepção dos sentidos no cotidiano das crianças, aliados a percepção intuitiva observado e presente na aprendizagem.

Existia nesse momento a ideia de que o Brasil, enquanto sociedade, tinha um aspecto, "atrasado, faltoso, errado no seu itinerário - e poderia passar para o moderno, civilizado, pela intervenção da educação e da maquinaria (WARDE, 2000, p. 10). O modelo americano, seria um "parâmetro de progresso" (ibid, p. 11), seria um exemplo de modernidade a ser seguida, como modelo.

Tal seria o panorama histórico, resumidamente, naquele momento: a necessidade de melhor preparar os alunos do curso primário para os anos seguintes. A matemática poderia ter um papel importante, na preparação dos alunos.

Educadores e profissionais interessados em contribuir nessas discussões passam a, entre outras situações, procurar outras maneiras de ensinar e contribuir com o "progresso" da sociedade. A contribuição estadunidense ${ }^{1}$, para alguns professores, seria um importante veículo de "parâmetro de progresso" (WARDE, 2000, p. 11).

Na educação, na década de 1910, temos assim, uma busca de entender, entre outras situações, na educação americana primária, o Relatório do Comitê dos Quinze (1895). Este, é apropriado por alguns autores brasileiros, como Antônio Bandeira Trajano, Tito Cardoso de Oliveira e Otelo de Souza Reis, no tocante ao ensino de matemática, em especial, sobre a álgebra no curso primário (VALENTE, 2016; 2017).

Nesse documento americano, existia a recomendação de não ensinar a álgebra no curso primário, mas que se deveria utilizar dela para o ensino de resolução de alguns problemas aritméticos (ROCHA, 2019).

Este ensino poderia auxiliar, segundo estudos de Valente $(2016 ; 2017)$ a preparar melhor os alunos para os cursos posteriores ao primário. Seria, uma possível contribuição para os últimos anos do curso primário e consequentemente, para os estudos posteriores deles.

Nesse período eram comuns discussões curriculares, na educação, visando diferentes projetos de uma sociedade moderna, elas envolviam

[...] abordagens científicas da educação emergentes e novas concepções sobre a criança, o ensino e o currículo. A questão da correlação dos estudos foi um dos aspectos sobre o qual os educadores polemizaram. Ela foi defendida pelos herbartianos, que nas décadas de 1880 e 1890 se consagraram como a vanguarda do pensamento científico em educação e também por Francis Parker,

${ }^{1}$ Aqui entende-se como modelos educacionais, que tem como perfil a pedagogia americana, nesse caso, um deles, o "Relatório do Comitê dos Quinze" (1895). Mais informações, podem ser encontrados em Valente (2016;2017), Warde (2000); Souza (2016). 
cujos trabalhos na direção da Quincy School foram marcados pela busca da inovação educacional (SOUZA, 2016, p. 37).

Uma inovação educacional importante a esse período vem do contato com a psicologia na educação, apresentada à "Associação Brasileira de Educação", por meio do Relatório do Comitê dos Quinze, escrito em 1895 (MONROE, 1989), como uma importante prescrição de como ensinar e o que ensinar no curso primário em várias matérias, entre elas, na matemática, que nos interessa.

A esse tempo, as duas capitais em que circularam os livros didáticos analisados nesse trabalho, vivenciavam momentos históricos importantes: Rio de Janeiro, como capital brasileira, foco, entre outras de exposições com as tendências educacionais e Belém do Pará, uma capital, que segundo Moreira (1989), presenciava, grande evidência financeira, educacional, sendo até mesmo, independente em produção de livros didáticos para o curso primário.

No Rio de Janeiro, encontramos o livro didático de Otelo de Souza Reis, cuja edição é datada de 1919, mencionando e constando, diretamente, sua orientação de utilizar de recursos que facilitem a resolução dos problemas aritméticos, acrescentando ainda que

[...] todos os problemas importantes aqui encontrareis por eles abordados e, sem superfetação de doutrinas, abstrações e filosofias, sem verbiagens nem preconceitos, referidas em termos claros e positivos as soluções que parecem mais práticas (REIS, 1919, prefácio, p. vi).

Este autor traz um longo prefácio - com 28 páginas - que se assemelham a um discurso para os professores utilizarem da álgebra para facilitar a resolução dos problemas aritméticos, não qualquer problema, mas aqueles que

[...] ora são problemas realmente difíceis, ora questões relativamente fáceis, mas cuja solução se tornam necessárias tantas palavras, tantas perífrases, tantas circunstancias que o aluno, depois de um grande esforço cerebral, do exercício, não aufere proveito mental aproveitável (REIS, 1919, prefácio, p. vi).

Logo, o "método algébrico" seria o ideal para a resolução desses exercícios, pois viria para auxiliar no processo desse exercício, que a princípio seria um exercício aritmético, ainda que o professor que ensina matemática, não estivesse ali familiarizado, com a álgebra, pois

[...] habituaram a considera-la como uma disciplina alheia à escola primária, e é tudo. Mas eu vos asseguro que não há propriamente - a álgebra, mas o método algébrico, que podeis ensinar, porque ensinaes coisas infinitamente mais dificeis. Podeis e deveis, porque as matérias de vossos programas crescem todos os dias, o aluno tem de aprender cada vez mais, e em pouco tempo, e nós não temos o direito de o privar de um meio fácil, rápido e cômodo de vencer numerosas dificuldades matemáticas. (REIS, 1919, prefácio, p. ix, grifos do autor).

O método algébrico seria um meio de facilitar o processo, como já alertara Valente $(2016 ; 2017)$, a álgebra e o método que dela viria seria, para os problemas aritméticos, um facilitador para as resoluções. 
Tal método parece ter sido proposto na capital do Pará, em período semelhante - década de 1910 - e com uma abordagem também parecida, como veremos adiante, nesse texto. Este livro didático foi escrito por Tito de Oliveira ${ }^{1}\left(\mathrm{~s} . \mathrm{d}^{2}\right.$.) e é considerado em seu estado como um "fenômeno" de edições em aritmética (MOREIRA, 1989). Em seu prefácio, Tito de Oliveira (s.d.) é anunciado como:

[...] apologista do método que manda incluir no estudo a Aritmética primária algumas noções necessárias para a resolução de pequenos problemas, pelas equações algébricas, sem, entretanto, fazer-se um estudo direto de Álgebra, resolvemos adaptar à nossa "Aritmética Complementar" este vantajoso método, que embora não se Ihe poderá conhecer as muitas vantagens que trará ao ensino, não se lhe poderá negar o grande serviço que prestará às crianças, desenvolvendo-Ihes a inteligência e acostumando-as a raciocinar com método (TITO DE OLIVEIRA, prefácio, s/d).

Método que também seria aplicado nos problemas, cuja característica importante seria substituir a quantidade desconhecida, cuja solução já seria procurada antes, mas somente, de maneira aritmética, pela letra $x$, como convenção a ser apresentada pelo professor.

Com os alunos, os professores que ensinam matemática deveriam estudar, assim as interpretações dos enunciados, aqueles que seriam parecidos a charadas ou enigmas, transformando-os em

[...] uma egualdade [que] pode e deve passar para ser resolvida, e thes teremos dado todos os conhecimentos para a resolução das equações algébricas do $1^{0}$ grao a uma incógnita, tornando-os, portanto, aptos a resolverem os problemas por este processo sem que se thes tenha falado em Algebra, nem feito um estudo direto dessa matéria (TITO DE OLIVEIRA, s.d. prefácio, p. 2).

Assim, se deveria evitar uma sequência, na aprendizagem cuja

[...] acrobacia de palavras e esse trabalho excessivo do cérebro, que, entende a pedagogia moderna, deve-se trazer para a escola primária, o método algébrico.

Não há, senhores professores, como justificar aqueles que, achando a aritmética uma valiosa ginastica mental, dela abusam, convertendo-a em instrumento de suplicio (REIS, 1919, prefácio, p. viii).

Os alunos deveriam utilizar então, as quantidades desconhecidas com a letra $x$, interpretar os enunciados e então proceder as operações aritméticas que estariam acostumados, ou seja, uma das quatro operações fundamentais da aritmética: adição, subtração, multiplicação ou divisão.

Este seria um ponto em comum, na proposta de ambos os autores, para o uso da álgebra, como um método, que iniciaria com a transformação do enunciado em uma equação, cuja quantidade desconhecida seria convencionada pela letra $x$.

O que diferenciam as propostas de Reis (1919) e Tito de Oliveira (s.d.), são a forma como essa marcha, os passos que o professor deveria conduzir o método algébrico.

${ }^{1}$ Aqui e em outros trabalhos de nossa autoria, chamamos de Tito de Oliveira, o autor Tito Cardoso de Oliveira, para evitar confusão com o pesquisador do GHEMAT, Marcus Aldenisson de Oliveira.

${ }^{2} \mathrm{~A}$ edição que está digitalizada e utilizada em nossas análises é de número 8 e não tem ano, no entanto, contém um prefácio de sua $4^{a}$ edição, datada de 1919.

(c) (1) P) Perspectivas em Diálogo, Naviraí, v.8, n. 16, p. 60-71, jan./abr. 2021. 


\section{Para resolver os problemas aritméticos, como propor o método algébrico?}

Aqui, importa reforçar que a maneira de propor seu método, pelos autores, está vinculada ao saber profissional necessário para que o professor ensinasse a resolução daqueles problemas.

Encontra-se relacionada - essa maneira de conduzir a resolução - a uma matemática para ensinar (BERTINI; MORAIS; VALENTE, 2017), própria para essas resoluções e para o curso primário, o professor esteve em contato, em sua formação com a álgebra ${ }^{1}$, conhecia esses saberes e deveria conduzir seus alunos, para facilitar os processos de resoluções, cujos enunciados fariam parte do cotidiano das crianças.

Reis (1919) já assume no início de sua obra os problemas do tipo charadas ou enigmas, eles, segundo o autor,

[...] podem e devem ser dedicados ao método algebrico de lidar com os problemas, pelo menos com os problemas difíceis, e ainda, que esse método pode ser ensinado logo após as quatro operações sobre inteiros e quebrados (REIS, 1919, prefácio, p. viii, grifos do autor).

Caberia ao professor que ensina matemática, ilustrar e ensinar aos alunos que a letra $x$, convencionada como uma quantidade desconhecida e que ainda assim, passa por todas as operações aritméticas habituais, que

[...] se o alumno estiver perfeitamente convencido de que $x$ é uma coisa, não hesitará, porque, do mesmo modo que em 16 caixas, cada uma com 4 maçãs, sabe que há ao todo 4 maçãs, repetidas 16 vezes, ou $4 \times 16=64$ maçãs em 16 caixas, cada uma com $4 x$, sabe que há ao todo $4 x$ repetidos 16 vezes, ou $4 \times \times 16=64 x$. (REIS, 1919, prefácio, p. xiii).

No entanto, temos que, para Tito de Oliveira (s.d.) a proposta é estabelecer uma marcha de ensino (BERTINI; ROCHA, 2018) em que esteja bem definidos os passos: regra, exemplos, exercícios e os problemas aritméticos, de uma maneira pausada e definida como ilustra a orientação abaixo, entre outras, presentes em seu livro didático: "Sendo muito comum nos problemas o emprego do dobro, do triplo etc., dos números, será de bom aviso ao professor exercitar os seus alunos o mais possível a esse respeito" (TITO DE OLIVEIRA, s.d., p. 42).

Dobro, triplo, quadruplo, metade, terça parte, parecem ser temas em comum nos enunciados desses problemas aritméticos, considerados adequados para 0 emprego do método algébrico (ROCHA, 2019). Ainda que de formas diferentes, ambos os autores parecem concordar com essa condição de emprego: leitura e interpretação dos textos dos enunciados e transformá-los em equações para operacionalizar os números de maneira aritmética.

Podemos sintetizar e considerar que esses passos que utilizam da álgebra como um saber profissional para ensinar aritmética, ou como uma álgebra para ensinar a resolver os problemas aritméticos (ROCHA, 2019), podem ser caracterizados numa sequência, em comum, em que

[..] importava ao professor que ensina matemática conhecer os passos dessa marcha:

${ }^{1}$ Tais recomendações foram encontradas nos programas de ensino dos dois estados: Rio de Janeiro e Pará, conforme ilustra Rocha (2019). 
a) Apresentar aos alunos a quantidade desconhecida dos problemas aritméticos a serem conhecidos como uma espécie, a incógnita $x$;

b) Caberia a esse professor primário ensinar às crianças que essa incógnita $x$ é uma espécie a sofrer as operações fundamentais: adição, subtração, multiplicação ou a divisão;

c) Essa quantidade desconhecida, agora conhecida por $x$, é o ponto de partida para a transformação dos dados;

d) A partir da incógnita $x$ estabelecida e utilizando de expressões como: dar, vender, comprar, gastar, mais, menos, retirar, entre outras, as operações fundamentais seriam acrescentadas na marcha do raciocínio e à incógnita $x$, de forma que satisfaça a sentença;

e) Ao se resolverem cálculos aritméticos que envolvessem as quatro operações fundamentais, o resultado dessa operação seria a quantidade a ser descoberta, satisfaria a equação e explicaria a problemática proposta;

f) Esta transposição dos dados para a operação levaria à formalização de um algoritmo a ser reconhecido entre as quatro operações fundamentais;

g) Só então o problema aritmético seria resolvido (ROCHA, 2019, p. 93).

Ainda que o ensino de álgebra para o curso primário não estivesse enquanto proposta, consideramos que o método algébrico utilizaria dela, enquanto saber profissional do professor que ensina matemática.

\section{Considerações finais}

Para efeito de retomada dos objetivos desse texto, considera-se que na busca de responder à questão: como está caracterizada a álgebra no ensino primário para resolver os problemas aritméticos nos livros didáticos de Reis (1919) e Tito de Oliveira (s.d.) na década de 1910? Foram percorridos, na intenção dessa resposta, alguns caminhos próprios da pesquisa que ilustraram algumas situações.

Dentre elas, destaca-se que na década de 1910, as capitais, Rio de Janeiro e Belém do Pará, vivenciavam momentos de relevância, em que as ideias renovadoras aconteciam em feiras, exposições, ou seja, por estar vivenciando, momentos de franca expansão da economia, como as riquezas que escoavam da extração da borracha, em Belém do Pará.

Seria importante para essas capitais, estar presentes nas discussões e propostas de como o ensino poderia melhorar, como poderiam contribuir para um curso primário que poderia propor um ensino mais adaptado a seu período histórico.

Assim, por estas capitais circularam ideias renovadoras para a educação, em especial, para o curso primário e sua formação de professores, aqui, nos referimos aos saberes propostos em matemática, nos problemas aritméticos.

No período em que os grupos escolares, eram exemplos de investimento e modernidade em seus locais, a formação de professores e em especial, aqueles da docência em matemática, no ensino primário, recebiam amplas discussões de caráter intencional a acompanhar a modernidade, esperada para aquele período.

O aluno, nesse período, do método intuitivo, deveria ser o centro da aprendizagem, caberia ao professor, como vimos, o papel de facilitar o aprendizado, movido pelo cotidiano do aluno que deveria promover o seu interesse.

Este interesse, deveria estar vinculado à aprendizagem de Matemática, e em especial, pelo aspecto possível para essa aprendizagem: o método algébrico para facilitar a resolução de problemas aritméticos. 
Problemas que teriam aspectos de charadas ou enigmas, assim, temos um tipo de problemas aritméticos a serem ensinados por meio do método algébrico, com temas, que envolviam dobro, triplo, metade, entre outros temas, cujos enunciados seriam transformados em equações e estas resolvidas, de maneira aritmética, seriam, logo, reduzidas a uma das quatro operações fundamentais que já conheciam: adição, subtração, multiplicação ou divisão.

Assim, a álgebra se apresenta para professor que ensina matemática, como um saber profissional que esteve presente na formação de professores, mas que também estaria sendo utilizada num método proposto por dois autores: Otelo de Souza Reis e Tito Cardoso de Oliveira.

Tal proposta está vinculada ao saber profissional desse professor de matemática, pois a álgebra era um saber presente na formação, mas não no ensino, como verificado na pesquisa que origina esse texto. Logo, o professor poderia utilizar e determinar como se daria esse processo, na dinâmica sugerida pelos autores dessas obras, pois ele determina o ritmo dessa marcha, segundo recomendações aos professores, presentes nesses dois livros didáticos aqui analisados, como um método para auxiliar a resolver os problemas aritméticos.

Dessa maneira, considera-se que a álgebra está definida como uma álgebra para ensinar a resolver problemas aritméticos, cujos enunciados, possuem caracterizações de enigmas ou charadas, com temas como dobro, triplo, metade, entre outros, a ser ensinada em ritmos próprios determinados por cada autor e pelo professor.

Apontamos a necessidade de pesquisas posteriores, pois estas podem ilustrar aspectos da formação de professores, com outros livros didáticos, revistas pedagógicas e outras fontes, para que possam ser ilustradas essa álgebra para ensinar a resolver os problemas de aritmética, presentes no ensino primário.

Reforçamos que, nas obras foram encontrados discursos para que o professor primário utilizasse do método algébrico, como uma maneira de facilitar determinados tipos de problemas aritméticos, como já mencionado nesse texto, e não necessariamente que fosse somente esse a maneira melhor de utilização ${ }^{1}$.

Importa mencionar, nesse momento, que as pesquisas que levam em consideração os saberes podem ilustrar mudanças na formação de professores, aqui nesse trabalho, formação de professores primários, pois ilustram as finalidades dos saberes ao longo de uma historicidade própria.

\section{REFERÊNCIAS}

BERTINI, Luciane de Fatima; MORAIS, Rosilda dos Santos; VALENTE, Wagner Rodrigues. A matemática a ensinar e a matemática para ensinar: novos estudos sobre a formação de professores. 1. ed. São Paulo: Editora Livraria da Física, 2017.

BERTINI, Luciane de Fatima.; MORAIS, Rosilda dos Santos; VALENTE, Wagner Rodrigues; ROCHA, Ivone Lemos da. "Resolução de problemas pelas equações algébricas": a proposta de Tito de Oliveira para o ensino das operações. Revista 
de História da Educação Matemática - HISTEMAT - n.03, v.4, p. 44 - 53, jan. 2018. Disponível em:

http://www.histemat.com.br/index.php/HISTEMAT/article/view/234/178. Acesso em: 18 jun. 2020.

BORER, Lussi Valérie. Saberes: uma questão crucial para a institucionalização da formação de professores. In: HOFSTETTER, Rita; VALENTE, Wagner Rodrigues. (orgs.). Saberes em (trans)formação: tema central da formação de professores. Livraria da Física, 2017, p. 173- 200.

BURKE. Peter. O que é história do conhecimento? Tradução Claudia Freire. $-1^{a}$ ed. - São Paulo: ed. Unesp, 2016.

CHARTIER, Roger. A História Cultural entre práticas e representações.

Tradução de Maria Manuela Galhardo. Portugal, Difusão Editorial, 2a ed., 1990.

CHOPPIN, Alain. O historiador e o livro escolar. História da Educação, ASPHE/ FaE/ UFPel, Pelotas, v. 6, n. 11, jan./jun. 2002, p. 5-24, set./dez., 2004. Disponível em: https://seer.ufrgs.br/asphe/article/view/30596. Acesso em: 16 abr. 2020.

CHOPPIN, Alain. O manual escolar: uma falsa evidência histórica. História da Educação, Pelotas, ASPHE, v. 13, n. 27, p. 9-75, jan./abr. 2009. Disponível em: https://seer.ufrgs.br/asphe/article/view/29026. Aceso em: 16 abr. 2020.

FARIA FILHO, Luciano Mendes de. Instrução elementar no século XIX. In: LOPES, Eliane M. T.; VEIGA, C. G. (orgs.). 500 anos de Educação no Brasil. São Paulo, Livraria Autêntica, 2016, p. 135-150.

HOFSTETTER, Rita; SCHNEUWLY, Bernard. Saberes: um tema central para as profissões do ensino e da formação. In Hofstetter, Rita.; Valente, Wagner Rodrigues. Saberes em (trans)formação: tema central da formação de professores. São Paulo: Editora Livraria da Física, 2017, p. 113-172.

LE GOFF. História e memória. 2. ed. Campinas. Editora da Unicamp, 1992, p. 462- 473. https://www.ufrb.edu.br/ppgcom/images/Hist\%C3\%B3riaeMem\%C3\%B3ria.pdf .

Acesso em: 15 abr. 2020.

JULIA, Dominique. A cultura escolar como objeto histórico. Tradução de Gisele Souza. Revista Brasileira de História da Educação, Campinas, SP. n. 01, jan./jun. 2001, pp. 9-43. Disponível em: https://docplayer.com.br/17300530-Aculturaescolar-como-objeto-historicodominique-julia.html. Acesso em: 15 abr. 2020.

MONROE, Paul. História da educação (Do original inglês: A Brief in the History of Education). Nova tradução e nota de Idel Becker, 14a ed. Ed. Nacional, Atualidades Pedagógicas, vol. 34. São Paulo, SP, 1989. 
MOREIRA, Eidorf. Obras reunidas de Eidorfe Moreira, vol. VI. Belém: CEJUP, 1989.

NÓVOA, Antônio. (Org.). o passado e o presente dos professores. Coleccção Ciências da Educação. Porto, Porto Editora, 2a ed., 1995, p. 13-34.

REIS, Otelo de Souza. Algebra - primeiros passos. Rio de Janeiro, 1919.

Disponível em https://repositorio.ufsc.br/handle/123456789/159574. Acesso em: 10 jul. 2020.

ROCHA, Ivone Lemos da. Os problemas aritméticos no Ensino primário, 1890-1940. In: Anais [...] Pelotas - Rio Grande do Sul, 2 a 4 de novembro de 2017, pp. 1-9. Disponível em: https://wp.ufpel.edu.br/xxiebrapem/anais-xxi-ebrapem-2/ . Acesso em: 12 jul. 2020.

ROCHA, Ivone Lemos da. Álgebra para resolver problemas: as propostas de Otelo de Souza Reis e Tito Cardoso de Oliveira, década de 1910. 2019. $105 f$. Dissertação. Mestrado em Ciências: Educação e Saúde na Infância e Adolescência Universidade Federal de São Paulo. São Paulo.

ROCHA, Ivone Lemos da. Problemas aritméticos e suas resoluções algébricas: um breve estudo em manuais pedagógicos, 1890-1940. In: Anais [...], Boa Vista Roraima, 11 a 13 de abril de 2018, pp. 1-12. Disponível em:

http://xviseminariotematico.paginas.ufsc.br/comunicacoes-cientificasdo-dia-1104/ . Acesso em: 15 jul. 2020.

ROCHA, Ivone Lemos da. O método algébrico estadunidense e os problemas aritméticos na proposta de Otelo de Souza Reis. In: Anais [...], Aracaju - Sergipe, 29 de abril a 01 de maio de 2019, pp. 1-14. Disponível em:

http://xviiseminariotematico.paginas.ufsc.br/sessao-de-comunicacao-3/ . Acesso em: 12 jun. 2020.

TANURI, Leonor M. História da formação de professores. Revista Brasileira de Educação, São Paulo, n. 14, p. 61-193. mai./jun./jul./ago/2000. Disponível em: http://www.scielo.br/pdf/rbedu/n14/n14a05 . Acesso em 10 jun. 2020.

TITO DE OLIVEIRA, Cardoso. Arithmetica Complementar para os cursos primário complementar, normal e comercial. Pará, [s.d.]. Disponível em: https://repositorio.ufsc.br/handle/123456789/1635. Acesso em: 10 jul. 2020.

SOUZA, Rosa Fátima. As disputas pelo currículo e a renovação da escola primária nos Estados Unidos na transição do século 19 para o século 20. Revista História da Educação (on-line), Porto Alegre, v. 20, n. 48, jan. abr./ 2016, pp. 35-53. Disponível em: http://www.scielo.br/pdf/heduc/v20n48/1414-3518-heduc-20-4800035.pdf. Acesso em: 10 jul. 2020.

VALENTE, Wagner Rodrigues. A álgebra na formação do professor primário: cenas de mudança no saber matemático para ensinar. In: Anais [...] Natal, RN, 2016. 
Disponível em:

http://xivseminariotematico.paginas.ufsc.br/files/2016/02/VALENTE_T3.pdf . Acesso em: 10 jul. 2020.

VALENTE, Wagner Rodrigues. A Matemática para o Professor dos Primeiros Anos Escolares - a Álgebra Entre a Cultura Enciclopédica e a Formação Profissional.

Jornal Internacional de Estudos em Educação Matemática (JIEEM), n०01, vol.10, 2017. Disponível em:

https://repositorio.ufsc.br/xmlui/handle/123456789/185669. Acesso em: 12 jul. 2020.

VALENTE, Wagner Rodrigues et al. A matemática na formação de professores e no ensino: processos e dinâmicas de produção de um saber profissional, 1890-1990. Projeto de Pesquisa. São Paulo: FAPESP, 2017.

WARDE, Mirian Jorge. Americanismo e educação um ensaio no espelho. São Paulo em Perspectiva, São Paulo, vol. 14, n. 2, abr./jun. 2000. Disponível em: https://www.scielo.br/scielo.php?pid=s010288392000000200006\&script=sci_abstract/. Acesso em: 18 jul. 2020.

WARDE, Mirian Jorge. Notas sobre o "Americanismo" dos Estados Unidos de fins do século XIX e início do século XX. In: Anais [...], São Paulo, SP, 2011. Disponível em:

http://www.snh2011.anpuh.org/resources/anais/14/1302297316_ARQUIVO_Mirian. pdf Acesso em: 18 jul. 2020. 